\title{
New kidney immobilization method for percutaneous renal biopsy technique in cats. Operational aspects and complications ${ }^{1}$
}

\author{
Novo método de imobilização do rim para biopsia renal percutânea em gatos. Aspectos \\ operacionais e complicações
}

\begin{abstract}
Daniele Alves Silva ${ }^{\mathrm{I}}$, Izabela Teodoro Oliveira ${ }^{\mathrm{I}}$, Cecília Braga Laposy ${ }^{\mathrm{II}}$, Cristiane Aparecida Miranda Zacchi ${ }^{\mathrm{I}}$, Juliana Dalarossa Amatuzzi $^{\mathrm{III}}$, Alessandra Melchert ${ }^{\mathrm{IV}}$

IGraduate student, Veterinary Medicine, UNOESTE, Presidente Prudente-SP, Brazil. Helped with data collection and processing of informations. IIPhD, Full Professor, Veterinary Medicine, Department of Clinical Pathology, UNOESTE. Presidente Prudente-SP, Brazil. Performed haematological and biochemical analysis of the study.

II'MD, Resident, Veterinary Medicine, UNOESTE, Presidente Prudente-SP, Brazil. Acquisition of data and technical support.

${ }^{\mathrm{IV}} \mathrm{PhD}$, Full Professor, Veterinary Medicine, Department of Clinical Pathology, UNOESTE, Presidente Prudente-SP, Brazil. Main author. Conception, design, intellectual and scientific content of the study.
\end{abstract}

\begin{abstract}
PURPOSE: Evaluate a new immobilization kidney method for collecting blind percutaneous renal biopsies (RB) in healthy cats.

METHODS: Ten cats were biopsied by a modified blinded percutaneous technique using semi-automated needles. Were evaluated the operational aspects of the technique, its complications, and the quality of the obtained samples. The evaluation included physical examination, hemogram, urinalysis, abdominal ultrasound, renal function, and histopathology of the biopsy specimens.

RESULTS: The developed technique was fast and easy to perform; it required two operators, and the right kidney was elected for specimen collection. After the RB, a decrease in hematocrit levels was observed in addition to hematuria and perirenal transient hematoma; however, no clinical consequences were observed, and normal parameters were restored within 48 hrs. There were no major complications or deaths, alterations in the physical examination or renal function, or signs of infection. Of the samples, $95 \%$ revealed the presence of renal tissue, and in $100 \%$ of the cats the samples were of diagnostic quality. CONCLUSION: The technique was easily performed, provided adequate material for diagnosis with minimal transient complications.
\end{abstract}

Key words: Kidney. Biopsy. Urology. Techniques. Complications. Cats.

\section{RESUMO}

OBJETIVO: Avaliar um novo método de imobilização do rim para coleta de biopsia renal (BR) percutânea às cegas em gatos hígidos. MÉTODOS: Dez gatos foram biopsiados por uma técnica de biopsia percutânea às cegas modificada, com uso de agulha semiautomática. Foram avaliados os aspectos operacionais da técnica, complicações e a qualidade das amostras obtidas. A avaliação incluiu exame físico, hemograma, urinálise, ultrassonografia abdominal, função renal e análise histopatológica do espécime de biopsia.

RESULTADOS: A técnica foi de fácil realização; foram requeridos dois operadores, e o rim direito foi eleito para a coleta da BR. Após a BR, diminuição do hematócrito foi observada, em conjunto com hematúria e hematoma peri-renal transitório; entretanto, não foram observadas conseqüências clínicas, e os parâmetros normais foram restabelecidos em 48 horas. Não ocorreram complicações maiores ou óbitos, alterações ao exame físico, função renal ou sinais de infecção. Das amostras obtidas, 95\% revelaram presença de tecido renal, e em $100 \%$ dos gatos as amostras apresentaram qualidade para diagnóstico.

CONCLUSÃO: A técnica foi realizada facilmente, forneceu material adequado para diagnóstico, com complicações clínicas mínimas. Descritores: Rim. Biópsia. Urologia. Técnicas. Complicações. Gatos. 


\section{Introduction}

Kidney diseases are common in cats ${ }^{1}$. Accurate assessment of the history, physical examination, laboratory tests, and diagnostic imaging may indicate alterations consistent with renal disease ${ }^{2}$ but may not determine the specific diagnosis ${ }^{3}$ or possibility of recovery of renal function ${ }^{2}$. The renal biopsy is a complementary test to these exams ${ }^{4}$.

Besides providing guidelines for therapeutic aid, the renal biopsy (RB) specimen displays diagnostic and prognostic value. However, this procedure is not frequently performed in cats due to complications associated with the procedure as well as the doubts in relation to the diagnosis ${ }^{1}$.

The biopsy and histopathological evaluation of the renal tissue are valuable diagnostic and prognostic tools ${ }^{5}$. The RB allows the clinician to establish the histological diagnosis and should be considered when it could alter the clinical approach ${ }^{6}$ or facilitate the prognosis, including in patients with glomerular desease or acute renal failure (IRA) ${ }^{7}$. It also justifies the use of specific and expensive therapies, such as dialysis, in those patients with a favorable prognosis ${ }^{2}$.

Several RB techniques have been described in veterinary medicine, and one of these is percutaneous biopsy, which does not require surgical opening of the abdominal cavity ${ }^{5}$. The percutaneous biopsy can be performed by using imaging such as ultrasound 8,9 , or "blindly", which is done when the kidneys are immobilized by abdominal palpation. The blind technique is especially easy to be performed in this species due to the easy palpation of cat kidneys ${ }^{7}$.

Complications for the RB result from the penetration of the needle in large vessels, which include: severe hemorrhage and perirenal bleeding ${ }^{3,10-12}$. Hydronephrosis due to ureteral or renal pelvis obstruction by blood clots ${ }^{10}$ and death are uncommon complications $^{1}$. Hemorrhaging is the most important and most serious complication of the RB procedure ${ }^{10}$, and the patient should be monitored after the procedure ${ }^{13}$.

To evaluate the quality of the RB sample, it is important to consider if the number of glomeruli is sufficient to represent the renal parenchyma ${ }^{14}$. There is no standard established for veterinary medicine; however, various references in the literature indicate that the minimum number of glomeruli per sample is five $e^{7,14}$.

However, in clinical practice, we observed difficulties in a renal biopsy collection in cats, with the previously described methods ${ }^{1}$. Thus, the objective of this study was to describe a new method of the blinded percutaneous RB technique and to evaluate its complications and the diagnostic quality of the samples in healthy cats.

\section{Methods}

\section{Animal selection and ethical guidelines}

This study used 10 healthy adult male $(n=3)$ and female $(n=7)$ cats of undefined breed weighing between 3 and $5 \mathrm{~kg}$ that came from the cattery of the Institution of origin. In this study, we performed biopsies in the right $(n=9)$ or left $(n=1)$ kidney of these animals. The study was approved by the Research Ethics Committee of the Institution, filed under number 130/06.

\section{Kidney immobilization and biopsy collection}

After adequate liquid and food fasting, the cats, with their abdominal regions properly shaved, were anesthetized with $1 \mathrm{mg} /$ $\mathrm{kg}$ xylazine associated with ketamine $10 \mathrm{mg} / \mathrm{kg}$ intramuscularly, preceded by $0.004 \mathrm{mg} / \mathrm{kg}$ atropine applied under the skin. The animals were then placed in the left lateral position for palpation of the abdominal cavity and the right and left kidneys by positioning the fingers beneath the transverse apophysis of the lumbar vertebrae and selecting the kidney with better immobilization for biopsy (Figure 1A). The procedure is relatively easy and minimally invasive, and it was performed on an outpatient basis without the need of an operating room.

There was adequate antisepsis of the abdominal cavity, and the kidney to be biopsied was immobilized by an assistant who moved the kidney up with one hand and immobilized it sideways using the index and middle fingers of the other hand located in the cranial and caudal poles (Figure 1B). The collection of the $\mathrm{RB}$ was done using the blinded percutaneous technique. A small incision was made in the skin (Figure 1C), and the operator of the needle inserted it into the caudal pole of the kidney in the dorsoventral direction using one hand, while the other hand fixed the kidney in its ventral face (Figure 1D) to avoid movement during the procedure.

A 16 gauge, 4.5 in, semi-automated Tru-Cut type needle was used, which has automatic gathering of the internal cannula. Two to four punctures were completed per animal, in order to obtain at least two specimens macroscopically viable, taking place however a maximum of four punctures per cat. The needle was inserted into the cavity through the skin incision, surpassing the muscles until its introduction into the renal capsule, which offers resistance to passage of the needle and when the kidney is perforated. The internal cannula of the needle was immediately exposed, and the automatic gathering of the cannula was triggered for the collection of the renal fragment. After the RB, the small 
incision of the skin was sutured with a simple point (Figure 1F) and nylon thread 2-0, which was removed after $7 \mathrm{~d}$. Sanitization of the local area was performed using saline and povidone iodine immediately after and 24 and $72 \mathrm{hrs}$ after the RB.

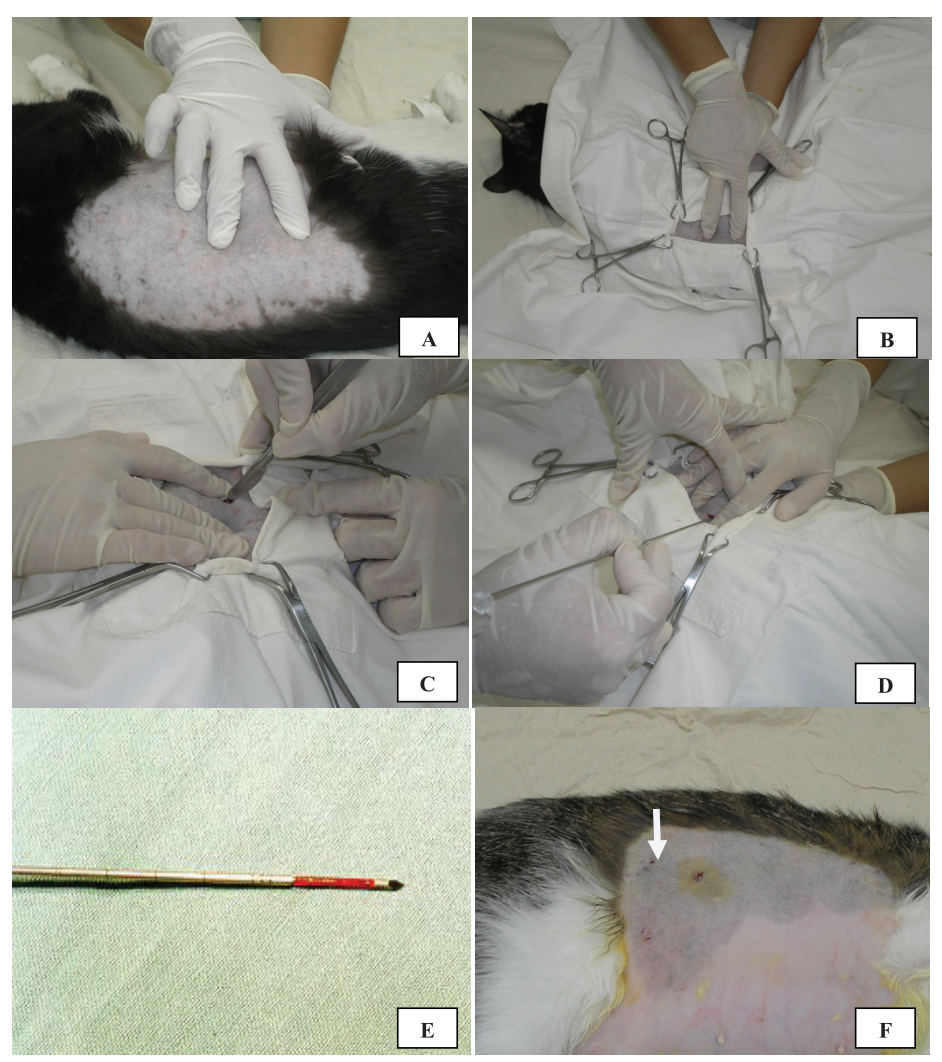

FIGURE 1 - A) Palpation of the abdominal cavity for localization and immobilization of the biopsied kidney; B) Immobilization of the kidney by the assistant using the index and middle fingers located in the cranial and caudal poles of the kidney; C) Small incision of the skin; D) Fixation of the kidney in its ventral face for later needle incision in its caudal pole by the needle operator; E) A core of renal tissue present in the exposed internal cannula of Tru-Cut needle; F) Surgical wound after the biopsy.

\section{Histopathology}

The fragments obtained in the biopsies (Figure 1E) were fixed in $10 \%$ neutral buffered formalin, processed and stained with hematoxylin-eosin. The quality of the samples was evaluated by the presence or absence of renal tissue and by the number of glomeruli present in the samples positive for kidney. Histological changes were examined by light microscopy analyses. Histological cuts with at least five glomeruli were considered of adequate quality for diagnosis ${ }^{7,14}$.

\section{Clinical evaluation}

The risks of percutaneous $\mathrm{RB}$ were evaluated using: complete physical examination, erythrogram, leukogram, and urinalysis before and 2, 24, and $48 \mathrm{hrs}$ after the RB (M0, M1,
$\mathrm{M} 2$, and $\mathrm{M} 3$, respectively); renal ultrasound before and $30 \mathrm{~min}$ after the RB to verify the occurrence of hemorrhaging or perirenal hematoma; urea and creatinine levels before and $72 \mathrm{hrs}$ after the $\mathrm{RB}$ to evaluate possible alterations in renal function; and coagulation time using the microcapillary method before the RB to exclude hemorrhagic tendencies. The biopsy site was inspected and palpated daily until removal of the suture stitches $(7 \mathrm{~d})$.

The complications observed in the study were classified as minimal: perirenal hematoma and microscopic hematuria, which spontaneously resolved without the need of a blood transfusion; and more serious: hemorrhages that required blood transfusion ${ }^{15,16}$.

\section{Statistical analysis}

The profile multivariate statistical analysis was used to analyze the data to compare the evaluation periods. All the data were analyzed using GraphPad Prism (version 1.3). The level of significance for the tests was 5\% (CI 95\%), and $\mathrm{p}<0.05$ was considered significant.

\section{Results}

According to the technique used, it was easier to perform the biopsy in the right kidney, which was palpated and immobilized with ease in nine animals (90\%), while the left kidney was selected in only one animal $(10 \%)$. The technique needed two operators, one elevating and immobilizing the kidney to a lateral position, while the other inserted a needle and fixed the kidney ventrally.

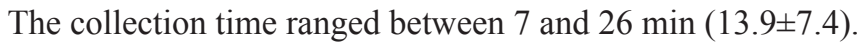

During the physical exam after the RB, there were no alterations in the vital parameters, and the presence of pain was not observed with abdominal palpation during any of the evaluation periods. The biopsy site, evaluated daily for $7 \mathrm{~d}$, remained without alterations or infection, despite the fact that no antibiotics were used. No alterations of the urea and creatinine serum levels were observed.

No major complications or deaths were observed, indicating that the technique is safe. There was no verified occurrence of major complications or deaths in the animals of this study. Among the minor complications, the occurrence of transitional macroscopic hematuria was observed in 2 (20\%) and perirenal hematoma in $1(10 \%)$ of the 10 biopsied animals, which totaled $30 \%$.

No changes were observed in the total number of leukocytes, which remained within the normal basal physiological values for the species at all times, indicating the absence of infection after the RB.

In the evaluation of the erythrogram, a significant 
decrease was observed in the parameters referring to the hematocrit, erythrocytes, and hemoglobin in M1 compared to the baseline (M0). However, in M2 and M3, these parameters showed a significant increase in relation to the $\mathrm{M} 1$, and did not differ from M0, which shows the transitional nature and prompt restoration of the blood count $24 \mathrm{hrs}$ after the RB. Table 1 shows the relative values of the hemogram.

TABLE 1 - Average values and standard deviation of the hematological parameters evaluated before (M0) and 2, 24, and 48 hrs (M1, M2, and M3) after the renal biopsy.

\begin{tabular}{ccccc}
\hline Parameters & M0 & M1 & M2 & M3 \\
\hline Hematocrit (\%) & $41.6 \pm 4.6$ & $30.36 .6^{*}$ & $40.5 \pm 3.2$ & $41.4 \pm 3.6$ \\
Erythrocytes (x 10 $)$ & $8.64 \pm 8.9$ & $6.48 \pm 1.2^{*}$ & $8.45 \pm 1.2$ & $8.95 \pm 1.2$ \\
Hemoglobin (g/dL) & $13.7 \pm 1.6$ & $9.92 .1^{*}$ & $13.1 \pm 1.4$ & $13.4 \pm 1.4$ \\
MVC (fL) & $43.5 \pm 15.4$ & $46.5 \pm 2.2$ & $49.0 \pm 8.4$ & $46.2 \pm 2.8$ \\
MCH (pg) & $15.8 \pm 1.0$ & $15.2 \pm 0.9$ & $15.6 \pm 2.6$ & $15.1 \pm 0.9$ \\
MCHC (\%) & $32.9 \pm 1.8$ & $32.8 \pm 2.0$ & $32.6 \pm 1.0$ & $32.8 \pm 1.1$ \\
Leukocytes (/mm $\left.{ }^{3}\right)$ & $13.9 \pm 4.5$ & $10.4 \pm 4.0$ & $14.5 \pm 5.7$ & $14.5 \pm 4.2$ \\
\hline
\end{tabular}

* p >0.001 X M0, M2 and M3

There was a significant increase in the number of erythrocytes in the urine in M1 and M2 compared to the control time M0; in M3, although there was no statistical difference when compared to M0, it was observed that the average number of erythrocytes was greater $(92.1 \pm 77.2$ in M3 versus $32.6 \pm 62.8$ in M0). Microscopic hematúria occurred in all cats of this study after RB. The occurrence of macroscopic hematuria was observed in two cats $(18.2 \%)$ and a significant decrease of the hematocrit $(p<0.001)$ only in M1 was observed, which reverted to the basal values from M2 on, indicating the transitional nature of the hemorrhaging. Only one of the cats tested showed evidence of bleeding in the ultrasound evaluation after the RB, with formation of a perirenal hematoma, which disappeared after $24 \mathrm{hrs}$.

There were two to four punctures completed per animal, resulting in one, two, or three fragments macroscopically viable in three $(30 \%)$, four $(40 \%)$, and three $(30 \%)$ animals, respectively. In $100 \%$ of the animals tested, at least one of the samples showed adequate material for diagnosis (i.e., five or more glomeruli per histological cut). Of the 20 fragments evaluated under the microscope, one $(5 \%)$ revealed the presence of muscle, while the other $19(95 \%)$ revealed the presence of renal tissue. Of these, only four fragments had no glomeruli, while one fragment showed the presence of only three glomeruli; in 14 samples (70\%), there were at least five glomeruli per histological cut.

\section{Discussion}

The RB, besides helping in the definition of the diagnosis, may also provide guidance on therapeutic aid and determine the prognosis of the patient ${ }^{1}$. This study evaluated the complications and quality of the samples of blinded percutaneous RB performed in cats and showed that by combining an experienced operator with the technique, adequate material can be obtained; the RB does not lead to serious complications; and in most cases it provides enough material for diagnosis. These results may serve as an incentive for clinicians to more frequently request for the use of this procedure; it is not often done in dogs and cats due to the associated complications and doubts about the diagnosis ${ }^{1}$.

Unlike the method of blinded percutaneous collection that has been described in the literature, which uses only one operator to perform the $\mathrm{RB}^{7,13}$, the technique used in this study requires two operators. However, immobilization of the biopsied kidney is adequate by not allowing movement during the insertion of the needle and ensures that, even without the help of images, such as ultrasound, the trajectory of the needle is accurate, the main advantage of the technique.

According to the literature, in cats, the technique of blinded percutaneous $\mathrm{RB}$ can be used to obtain fragments from both the right and left kidneys as both can be located and immobilized by abdominal palpation ${ }^{18}$. However, in this study, it was easier to perform the procedure in the right kidney, which was selected for the RB in nine animals (90\%). This may be due to the more constant position of the right kidney, once the left kidney is more loosely attached to the body wall ${ }^{18}$. Additionally, must be considered that the operator is right-handed and the cats were then placed in the left lateral position.

Hemorrhaging is the major complication after $\mathrm{RB}^{10}$, which was confirmed in this study. Among the alterations observed after the RB, there was a transitory decrease of the hematocrit, erythrocytes and hemoglobin and occurrence of hematuria. Therefore, the procedure should be avoided in patients with uncorrected severe coagulopathy ${ }^{19}$.

The magnitude of hemorrhaging can be monitored by the serial evaluation of the hematocrit of the animals that underwent the procedure ${ }^{13}$. Despite a decrease in the average values of this variable, none of the cats in this study needed a blood transfusion, 
which classifies the hemorrhaging as a minor complication ${ }^{15,16}$. Also, this decrease in the hematocrit values was transient, and 24 hrs after the RB these, values returned to normal.

Microscopic hematuria occurred in all cats of this study after the RB. This is a frequent finding in the first $48 \mathrm{hrs}$ after biopsy, although microscopic hematuria is less common and of small significance ${ }^{13}$. The self-limited microscopic hematuria often occurs within 12 hrs to $3 \mathrm{~d}$ after the $\mathrm{RB}^{3,13}$, and similar results were found in this study.

The ultrasound evaluation of the kidneys after biopsy may show evidence of hemorrhaging and its severity ${ }^{13}$. The occurrence of perirenal hematoma in one of the animals $(10 \%)$ of this study is greater than the rate described in the literature for dogs and cats. In one of the studies, the authors showed that no hematomas formed immediately or $24 \mathrm{hrs}$ after RB in $\operatorname{dogs}^{20}$, while another study revealed the formation of perirenal hematoma immediately after the procedure in $5.6 \%$ of the biopsied dogs and cats $^{21}$. However, this alteration was transient, as the hematoma disappeared after $24 \mathrm{hrs}$.

The technique and materials used for the renal biopsy in this study offered satisfactory results related to the quality of the obtained samples, revealing the presence of renal tissue with a minimum of five glomeruli per histological cut in at least one of the fragments obtained in 10 cats $(100 \%)$. These results are similar or even higher to the those observed in dogs and cats in the literature ${ }^{20,22-24}$. In a percutaneous renal biopsy in cats, an average of 9.7 glomeruli per histological cut was obtained and $33.3 \%$ of the samples contained muscle or adipose tissue ${ }^{24}$.

\section{Conclusion}

The new technique of blinded percutaneous $\mathrm{RB}$ in cats was easy to perform, and it permitted the gathering of biopsy specimens adequate for diagnosis and caused no serious hemorrhagic complications, demonstrating the safety of the technique.

\section{References}

1. Vaden SL, Levine JF, Lees GE, Groman PR, Grauer GF, Forrester SD. Renal biopsy: a retrospective study of methods and complications in 283 dogs and 65 cats. J Vet Intern Med. 2005;19(6):794-801.

2. Brovida C. Kidney Biopsies: How and When to Perform It? In: World Small Animal Veterinary Association World Congress Proceedings, 2003. Available from: <http://www.vin.com/ proceedings/Proceedings.plx?CID $=$ WSAVA2003\&Category $=1018$ $\& \mathrm{PID}=6536 \& \mathrm{O}=$ Generic $>$.

3. Osborne CA, Stevens JB, Perman V. Kidney biopsy. Vet Clin North Am Small Anim Pract. 1974;4: 351-65.

4. Corlouer JP, Patat JL, Darondel J. La biopsie rénale. Point Vet. 1984;16:31-3.

5. Rezaie A, Mousavi G, Mohajeri D, Asadnasab G. Complicatios of the ultrasound-guided needle biopsy of the kidney in dogs. J Anim Vet Adv. 2008;7(10):1207-13.

6. Lane IF, Grauer GF, Fettman MJ. Acute renal failure. Part II. Diagnosis, management, and prognosis. Compend Contin Educ Vet. 1994; 16:625-45.

7. Vaden SL. Renal biopsy of dogs and cats. Clin Tech Small Anim Pract. 2004;20:11-22.

8. Zatelli A, D'ippolito P, Zini E. Comparison of glomerular number and specimen length obtained from 100 dogs via percutaneous echo-assisted renal biopsy using two different needles. Vet Radiol Ultrasound. 2005;46(5):434-6.

9. Maya ID, Maddela P, Barker J, Allon M. Percutaneous renal biopsy: comparison of blind and real-time ultrasound-guided technique. Semin Dial. 2007;20:355-8.

10. Osborne CA. Clinical evaluation of needle biopsy of the kidney and its complications in the dog and cat. J Am Vet Med Assoc. 1971;158:1213-28.

11. Jeraj K, Osborne CA, Stevens JB. Evaluation of renal biopsy in 197 dogs and cats. J Am Vet Med Assoc. 1982;181:367-9.

12. Wise LA, Allen TA, Cartwright M. Comparison of renal biopsy techniques in dogs. J Am Vet Med Assoc. 1989;195:935-9.

13. Osborne CA, Bartges JW, Polzin DJ, Lulich JP, Johnston GR, Cox V. Percutaneous needle biopsy of the kidney. Vet Clin North Am Small Anim Pract. 1996;26:1461-504.

14. Laufer-Amorim R, Bandarra EP, Monteiro Júnior LA, De Moura VMBD. Avaliação quantitativa e qualitativa da técnica de biopsia renal "de janela" em cães. Ciênc Anim Bras. 2002;3:41-5.

15. Nyman RS, Cappelen-Smith J, AL Suhaibani H, Alfurayh O, Shakweer W, Akhtar M. Yield and complictions in percutaneous renal biopsy. A comparison between ultrasound-guided gun-biopsy and manual tchniques in native and transplant kidneys. Acta Radiol. 1997;38:431-6.

16. Mostbeck GH, Wittich GR, Derfler K, Ulrich W, Walter RM, Herold C, Haller J, Tscholakoff D. Optimal needle size for renal biopsy: in vitro and in vivo evaluation. Radiology. 1989;173:819-22.

17. Nash AS, Boyd JS, Minto AW, Wright NG. Renal biopsy in the normal cat: an examination of the effects of a single needle biopsy. Res Vet Sci. 1983;34:347-56.

18. Osborne CA, Fletcher TF. Applied anatomy of the urinary system with clinicopathologic correlation. In: Osborne CA, Finco DR. Canine and feline nephrology and urology. Baltmore: Lea \& Febiger; 1995.

19. Lefaucheur C, Nochy D, Bariety J. Renal biopsy: procedures, contraindications, complications. Nephrol Ther. 2009;5(4):331-9.

20. Hoppe FE, Hager DA, Poulos PW, Ekman S, Lindgren PG. A comparisation of manual and automatic ultrasound-guided biopsy techniques. Vet Radiol Ultrasound. 1986;27:01.

21. Léveillé R, Partington BP, Biller DS, Miyabayashi T. Complications 
after ultrasound-guided biosy of abdominal strutures in dogs and cats: 246 cases (1984-1991). J Am Vet Med Assoc. 1993;203:413-5.

22. Minkus G, Reusch C, Hörauf A, Breuer W, Darbés J, Kraft W, Hermanns W. Evaluation of renal biopsies in cats and dogs histopathology in comparison with clinical data. J Small Anim Pract. 1994;35:465-72.

23. Yamamoto K, Ishiyama N, Yamaga Y, Hayashi T, Kagota K. Ultrasound-guided techniques for biopsy of the kidney of the medium-sized dog. J Vet Med Sci. 1991;53:345-6.

24. Nash AS, Boyd JS, Minto AW, Wright NG. Renal biopsy in the normal cat: examination of the effects of repeated needle biopsy. Res Vet Sci. 1986;40:112-7.

\section{Correspondence:}

Alessandra Melchert

Rua Mário Boscoli, 95/31

190600-540 Presidente Prudente - SP Brasil

Tel.: (55 18)9753-3121

alessandravet@unoeste.br

Received: August 23, 2011

Review: October 25, 2011

Accepted: November 22, 2011

Conflict of interest: none

Financial source: UNOESTE

${ }^{1}$ Research performed at the Units of Medical Clinics in Small Animals, Clinical Pathology and Anatomical Pathology, Veterinary Hospital, University of Oeste Paulista (UNOESTE), Presidente Prudente-SP, Brazil. 